\title{
Peak individual alpha frequency qualifies as a stable neurophysiological trait marker in healthy younger and older adults
}

\section{THOMAS H. GRANDY, ${ }^{a}$ MARKUS WERKLE-BERGNER, ${ }^{a}$ CHRISTIAN CHICHERIO,,${ }^{\mathrm{a}, \mathrm{b}}$ FLORIAN SCHMIEDEK, MARTIN LÖVDÉN, a,d AND ULMAN LINDENBERGER ${ }^{\mathrm{a}}$}

${ }^{a}$ Center for Lifespan Psychology, Max Planck Institute for Human Development, Berlin, Germany

${ }^{b}$ Neuropsychology Unit, Neurology Clinic, Department of Clinical Neurosciences, Geneva University Hospital, Geneva, Switzerland ${ }^{\mathrm{c}}$ German Institute for International Educational Research (DIPF), Frankfurt am Main, Germany

${ }^{\mathrm{d}}$ Aging Research Center, Karolinska Institutet \& Stockholm University, Stockholm, Sweden

\begin{abstract}
The individual alpha frequency (IAF) of the human EEG reflects systemic properties of the brain, is highly heritable, and relates to cognitive functioning. Not much is known about the modifiability of IAF by cognitive interventions. We report analyses of resting EEG from a large-scale training study in which healthy younger $(20-31$ years, $N=30)$ and older (65-80 years, $N=28$ ) adults practiced 12 cognitive tasks for $\sim 1001$-h sessions. EEG was recorded before and after the cognitive training intervention. In both age groups, IAF (and, in a control analysis, alpha amplitude) did not change, despite large gains in cognitive performance. As within-session reliability and test-retest stability were high for both age groups, imprecise measurements cannot account for the findings. In sum, IAF is highly stable in healthy adults up to 80 years, not easily modifiable by cognitive interventions alone, and thus qualifies as a stable neurophysiological trait marker.
\end{abstract}

Descriptors: EEG, Alpha frequency, Reliability, Stability, Trait

The alpha frequency (AF) is the dominant frequency of the human electroencephalogram (EEG) during relaxed wakefulness and may tap into general central nervous system (CNS) functioning, as well as the status of mental health and cognitive functioning. Already Berger $(1929,1933)$ took up a two-fold perspective on AF. He assessed AF in order to monitor changes within subjects (intraindividual change), such as the deceleration of AF caused by intoxication and its acceleration paralleling recovery from intoxication. He also measured the AF for individual patients and healthy individuals to delineate differences between persons (interindividual differences), for example, in relation to cognitive ability.

Today, a vast amount of evidence supports and extends Berger's initial observations. Significant correlations between interindividual differences in $\mathrm{AF}$ and a large variety of cognitive measures have been observed (Angelakis, Lubar, \& Stathopoulou, 2004; Angelakis, Lubar, Stathopoulou, \& Kounios, 2004; Anokhin \&

This work was supported by the Max Planck Society (including a grant from the Innovation Fund: M.FE.A.BILD0005), the Sofja Kovalevskaja Award (to ML) administered by the Alexander von Humboldt Foundation and donated by the German Federal Ministry for Education and Research (BMBF), the German Research Foundation (DFG; KFG 163), and the BMBF (CAI). UL was financially supported by the Gottfried Wilhelm Leibniz Award of the DFG. We thank Colin Bauer, Annette Brose, and all research assistants involved in data collection.

Address correspondence to: Markus Werkle-Bergner, Center for Lifespan Psychology, Max Planck Institute for Human Development, Lentzeallee 94, 14195 Berlin, Germany. E-mail: werkle@mpibberlin.mpg.de
Vogel, 1996; Clark et al., 2004; Giannitrapani, 1985; Klimesch, Schimke, Ladurner, \& Pfurtscheller, 1990; Klimesch, Schimke, \& Pfurtscheller, 1993; Mundy-Castle, 1958; Mundy-Castle \& Nelson, 1960; Surwillo, 1961, 1963). Early theoretical accounts of this association suggested a link between AF and speed of information processing (cf. Klimesch, Doppelmayr, Schimke, \& Pachinger, 1996). More recent conceptions propose that alpha oscillations represent a general mechanism for the timing of neural inhibition (Klimesch, Sauseng, \& Hanslmayr, 2007; Mazaheri \& Jensen, 2010), and the gating of information flow in the brain (Jensen \& Mazaheri, 2010). Broad slowing of the EEG has been found to indicate CNS pathology (cf. Babiloni et al., 2008; Moretti et al., 2007; Prichep, 2007; Stomrud et al., 2010; Szelies et al., 1992; Szelies, Mielke, Kessler, \& Heiss, 1999). In particular, slowing of AF has been observed repeatedly in patients with dementia (cf. Cantero et al., 2009; d'Onofrio et al., 1996; Gawel, Zalewska, Szmidt-Salkowska, \& Kowalski, 2007, 2009; Jelic et al., 2000; Montez et al., 2009; Moretti et al., 2004). However, the majority of studies has been conducted from a between-person perspective, comparing different groups of individuals (e.g., with or without diagnosis of dementia) with respect to group differences in mean AF. Even though the mean AF of patient groups is often found to be slower than the mean $\mathrm{AF}$ of healthy controls, it generally is located within the AF distribution of healthy adults, which ranges from approximately 8 to $12 \mathrm{~Hz}$ (cf. Aurlien et al., 2004; Chiang, Rennie, Robinson, van Albada, \& Kerr, 2011; Niedermeyer \& Lopes da Silva, 1999). Hence, AF alone is of limited diagnostic value, as it fails to flag CNS pathology at the individual level. 
Within groups of healthy individuals, there are substantial and highly stable between-person differences in $\mathrm{AF}$ over test-retest intervals up to several years (Deakin \& Exley, 1979; Gasser, Bächer, \& Steinberg, 1985; Kondacs \& Szabó, 1999; Salinsky, Oken, \& Morehead, 1991). Thus, the AF of individual subjects exhibits characteristics of a stable marker of a neurophysiological trait, thereby justifying the term individual AF (IAF) for a given individual (see also Doppelmayr, Klimesch, Pachinger, \& Ripper, 1998; Klimesch, 1996, 1997). It has been shown that characteristics of the adult EEG-including features and variants of the alpha rhythm — show remarkably high heritability and thus are likely under strong genetic control (cf. Anokhin, Müller, Lindenberger, Heath, \& Myers, 2006; Anokhin et al., 2001; C. M. Smit, Wright, Hansell, Geffen, \& Martin, 2006; D. J. Smit et al., 2005; van Beijsterveldt \& Boomsma, 1994; van Beijsterveldt \& van Baal, 2002; Vogel, 1970), accounting well for the stable between-person differences in IAF.

Given the high stability of interindividual differences in IAF over time in the absence of neuropathological processes, IAF may be a valuable marker for monitoring neuropathological changes within individuals. That is, whereas absolute values of IAF may possess poor sensitivity and specificity as a clinical marker as argued above, IAF may constitute a promising and readily available candidate for monitoring deviations from normal CNS functioning, such as progression of disease, by following within-person changes over time.

The potential use of changes in IAF over time as an early individual marker of pathology mandates that IAF is, in fact, stable within individuals in the absence of pathology. In this context, two separate and formally independent aspects of stability need to be distinguished (cf. Kagan, 1980). One aspect is the stability of between-person differences in IAF, that is, stability of the rank order of IAF across individuals as reported above. The other aspect is the stability of the absolute IAF, for example, as expressed in the lack of change in IAF within individuals over time. Whereas the former has been investigated extensively, the stability of the absolute IAF over time has been rarely investigated explicitly. Furthermore, if stability of IAF reflects aspects of CNS functioning that are particularly difficult to modify through experience, then IAF should be robust against indirect influences on general CNS functioning such as practice-related improvements in a variety of cognitive tasks.

Here, we use data from the COGITO study (Schmiedek, Lövdén, \& Lindenberger, 2010) to investigate both aspects of the stability of IAF over half a year and as a function of extensive cognitive training in younger (20-31 years) and older (65-80 years) adulthood. In the COGITO study, a relatively large sample of individuals in an intervention group $(N=204)$ practiced a broad battery of perceptual speed, working memory, and episodic memory tasks for over 1001 -h sessions. A no-contact control group $(N=83)$ took part in an extensive cognitive assessment before (pretest) and after (posttest) the 100 days of cognitive training only. Approximately $30 \%$ of all participants took part in EEG recordings conducted in the context of the pretest and posttest assessments. IAF was assessed by fast Fourier transform (FFT) of the resting EEG, with $2 \mathrm{~min}$ eyes closed followed by $2 \mathrm{~min}$ eyes open, and subsequent peak detection in the alpha range of the frequency spectrum.

By examining training-induced changes at the level of latent factors, Schmiedek and colleagues (2010) were able to demonstrate that the cognitive intervention as implemented in the COGITO study led to improvements in broad cognitive abilities. In addition, diffusion tensor imaging in a subgroup of participants revealed training-related improvements in the integrity of white matter, confined to the anterior portion of the corpus callosum (Lövdén et al., 2010). Thus, the COGITO study offers a unique opportunity to investigate the stability of IAF in younger and older adults. Gauging the effects of prodromal or early dementia on IAF requires knowledge about the degree of IAF stability in healthy aging, which, to our knowledge, has not yet been fully determined.

\section{Method}

\section{Participants}

The current study analyzed data from a subsample of the COGITO study (cf. Schmiedek et al., 2010), conducted at the Max Planck Institute for Human Development (MPIB), Berlin, Germany. Participants were recruited through newspaper advertisements, wordof-mouth recommendation, and flyers circulated in Berlin, for a longitudinal study on training and day-to-day variability of cognitive performance. The total COGITO sample involved 101 younger adults (YA, aged 20-31 years) and 103 older adults (OA, aged 65-80 years) completing an average of 101 daily sessions of cognitive assessment (cognitive intervention/training phase) as well as an extensive assessment of a large battery of cognitive tasks before (pretest) and after (posttest) the cognitive intervention phase. In addition to this intervention group, a no-contact control group of 44 younger adults (age range 20-31 years) and 39 older adults (age range 66-82 years) was recruited for participating in the pretest and posttest only. The Ethics Committee of the MPIB approved the study. All participants gave written informed consent.

Approximately $30 \%$ of the parent sample also volunteered and were eligible for participating in EEG recordings that were conducted in the context of the pretest and posttest assessments, resulting in an effective sample for this report of 30 younger (17 women, $M_{\text {age }}=25.3$ years, $S D=3.1$, range $=20-31$ years $)$ and 28 older $(10$ women, $M_{\text {age }}=70.8$ years, $S D=4.0$, range $=65-80$ years) adults in the intervention group and 15 younger ( 7 women, $M_{\text {age }}=24.7$ years, $S D=2.3$, range $=22-29$ years) and 12 older adults (6 women, $M_{\text {age }}=69.2$ years, $S D=3.5$, range $=66-79$ years) in the control group. To be eligible, participants had to have normal or corrected-to-normal vision and be right-handed. In addition, they had to report not to suffer from any of the following conditions: cardiovascular disease, except for treated hypertension, present in seven older adults; diabetes; neurological or psychiatric conditions; use of antiseizure or antidepressant drugs; drug or alcohol abuse. Older participants were screened for dementia using the minimental state examination (MMSE; Folstein, Folstein, \& McHugh, 1975 ) with a cut-off score of 26 . Table 1 provides an overview of the sample descriptives. With respect to chronological age, Digit Symbol Substitution scores (perceptual speed), Raven Advanced Progressive Matrices scores (reasoning), and MMSE scores, the intervention and control group in the COGITO parent sample did not differ significantly from each other (independent samples $t$ tests, all $p \mathrm{~s}>.05)$, as did the EEG subsample and the non-EEG subsample (independent samples $t$ tests, all $p \mathrm{~s}>.05$ ). Thus the intervention and control group can be regarded as being comparable at pretest, and the EEG subsample as being representative of the full COGITO parent sample.

Within the EEG subsample, intervention and control group did not differ significantly with regards to chronological age (YA: $t(43)=0.64$; OA: $t(38)=1.16$; $p \mathrm{~s}>.05)$, Digit Symbol Substitution scores (YA: $t(43)=-0.90$; OA: $t(38)=-0.35 ; p$ s $>.05$ ), Raven 
Table 1. Descriptive Statistics and Individual Alpha Frequency With Eyes Closed and Eyes Open at Pretest

\begin{tabular}{|c|c|c|c|c|c|}
\hline \multirow[b]{2}{*}{ Younger adults } & & \multicolumn{2}{|c|}{ EEG subsample } & \multicolumn{2}{|c|}{ COGITO parent sample } \\
\hline & & $\begin{array}{l}\text { Intervention group } \\
\qquad(n=30)\end{array}$ & $\begin{array}{l}\text { Control group } \\
\quad(n=15)\end{array}$ & $\begin{array}{l}\text { Intervention group } \\
\quad(n=101)\end{array}$ & $\begin{array}{c}\text { Control group } \\
\quad(n=44)\end{array}$ \\
\hline & Age $(S D)$ & $25.3(3.1)$ & $24.8(2.3)$ & $25.6(2.7)$ & $25.2(2.5)$ \\
\hline & Digit symbol (SD) & $59.6(9.2)$ & $62.1(8.2)$ & $60.3(9.5)$ & $59.5(8.7)$ \\
\hline & Raven Matrices $(S D)$ & $.55(.21)$ & $.51(.15)$ & $.53(.21)$ & $.49(.18)$ \\
\hline & IAF EC $(S D)$ & $9.9(0.7)$ & $9.7(0.9)$ & - & - \\
\hline & IAF EO $(S D)$ & $10.1(0.8)$ & $9.8(1.1)$ & - & - \\
\hline \multirow[t]{7}{*}{ Older adults } & & $\begin{array}{l}\text { Intervention group } \\
\qquad(n=28)\end{array}$ & $\begin{array}{l}\text { Control group } \\
\quad(n=12)\end{array}$ & $\begin{array}{l}\text { Intervention group } \\
\qquad(n=103)\end{array}$ & $\begin{array}{l}\text { Control group } \\
\quad(n=39)\end{array}$ \\
\hline & Age $(S D)$ & $70.8(4.0)$ & $69.2(3.5)$ & $71.3(4.1)$ & $70.6(4.0)$ \\
\hline & Digit symbol $(S D)$ & $45.5(7.6)$ & $46.4(7.7)$ & $43.6(9.0)$ & $44.4(8.5)$ \\
\hline & Raven Matrices $(S D)$ & $.29(.15)$ & $.29(.18)$ & $.24(.15)$ & $.27(.14)$ \\
\hline & $\operatorname{MMSE}(S D)$ & $28.6(1.3)$ & $28.3(1.6)$ & $28.4(1.2)$ & $28.2(1.6)$ \\
\hline & IAF EC $(S D)$ & $9.4(0.9)$ & $9.2(0.6)$ & - & - \\
\hline & IAF EO $(S D)$ & $9.5(1.3)$ & $9.4(0.9)$ & - & - \\
\hline
\end{tabular}

Note. Differences between the intervention and control group in the full COGITO parent sample as well as in the EEG sub-sample were not statistically significant (independent samples Student's $t$ tests, all $p \mathrm{~s}>.05$ ). Also differences between the EEG subsample and the non-EEG subsample were not statistically significant (independent samples Student's $t$ tests, all $p$ s $>.05$ ). MMSE $=$ mini-mental state examination; IAF $=$ individual alpha frequency.

Advanced Progressive Matrices scores (YA: $t(43)=0.80$; OA: $t(38)=-0.06 ; p \mathrm{~s}>.05)$, mean IAF with eyes closed (YA: $t(43)=0.59$; OA: $t(37)=0.45 ; p s>.05)$, mean IAF with eyes open (YA: $t(43)=1.22$; OA $t(38)=0.19 ; p \mathrm{~s}>.05)$, and MMSE scores $(\mathrm{OA}: t(38)=0.84, p>.05)$, all as assessed at pretest (see Table 1).

\section{Study Design}

During the longitudinal training phase, the intervention group practiced six perceptual speed, three working memory, and three episodic memory tasks during on average 101 1-h sessions. Pretest and posttest assessments for the intervention as well as the control group consisted of 10 sessions of 2-2.5 h, containing cognitive test batteries and self-report questionnaires (e.g., personality inventories). Pretest EEG recording was conducted after the behavioral pretest and for the intervention group immediately before the longitudinal training phase. The posttest EEG recording was completed shortly after the completion of the behavioral posttest. The EEG recordings were separated by an average of 6.6 months for the intervention group (YA: $M=6.9$ months, $S D=1.0$; OA: $M=6.3$ months, $S D=1.0$ ) and equally by an average of 6.6 months for the control group (YA: $M=6.7$ months, $S D=0.8$; OA: $M=6.4$ months, $S D=0.8)$. Intervention and control group were statistically comparable on average temporal distance between EEG recordings (YA: $t(43)=0.51$; OA; $t(38)=-0.23 ; p \mathrm{~s}>.05$ ).

\section{Practice Sessions and Practiced Cognitive Tasks}

In each practice session, participants accomplished 12 different cognitive tasks from the cognitive domains of perceptual speed, working memory, and episodic memory. Within each cognitive domain, tasks consisted either of numerical (e.g., digits), verbal (e.g., letters), or figural-spatial (e.g., spatial positions) stimulus material. Sessions were carried out in small groups of two to five participants at PCs, using the keyboard, mouse, as well as special button boxes for the different tasks. All stimuli were presented on the computer screen. The practiced tasks will be briefly described below. For a detailed description of the tasks, see Schmiedek and colleagues (2010).

Six perceptual speed tasks were administered, consisting of three choice reaction tasks (CRTs) and three comparison tasks
(CTs). In the three CRTs, digits (numerical), letters (verbal), or lines (figural) were presented, followed immediately by a visual mask in order to increase perceptual difficulty. Participants had to decide as fast and accurately as possible whether the stimulus was odd or even (numerical), a consonant or vowel (verbal), or symmetric or asymmetric (figural). In the CTs, either two strings of five digits (numerical) or consonants (verbal), or two three-dimensional colored objects were presented. Participants had to decide as fast and accurately as possible whether each two strings or objects were identical or not.

Three different working memory (WM) tasks were administered. In a numerical memory updating task, participants had to concurrently update four digits, i.e., carrying out additions and subtractions on the digits, and memorize the updated result. Updating operations appeared on the screen, referring to the four different digits in random order. At the end of each trial, the four final results had to be reproduced. In the alpha span task, participants had to assess, in sequentially presented letter-digit pairs, whether the digit indicated the correct relative position of the letter within the alphabetically ordered letters presented up to that point. In a spatial 3-back task, a sequence of black dots appeared at randomly varying locations in a $4 \times 4$ grid. Participants had to recognize whether each dot was in the same position as the dot three steps earlier in the sequence or not.

Finally, three different episodic memory (EM) tasks were administered. In a word list task, lists of 36 nouns were presented sequentially and had to be recalled in the correct sequential order. In a number-noun pair task, lists of 12 pairs of two-digit numbers and nouns (e.g., "22 dogs") were presented sequentially. After presentation, the nouns appeared in random order and the corresponding numbers had to be entered. In an object position memory task, sequences of 12 colored photographs of real-world objects were displayed at different locations in a $6 \times 6$ grid. After presentation, presented objects appeared at the bottom of the screen and had to be moved with the computer mouse in the correct order to the correct locations.

To maximize and even out the cognitive challenge of these tasks across individuals while also maintaining motivation, difficulty levels for the CRT, episodic memory, and working memory tasks were individualized using different masking and presentation times 
based on pretest performance (for details, see Schmiedek et al., 2010).

\section{Assessment of Cognitive Training Effects}

To illustrate the cognitive training effects within the EEG subsample, we present results from the 12 trained cognitive tasks described above and as assessed during pretest and posttest (see Schmiedek et al., 2010, for further details). For the perceptual speed tasks (CRT, $\mathrm{CT}$ ), accuracies and mean response times are reported; for the working memory (WM) and episodic memory (EM) tasks, accuracies are reported (see Table 2). For the overall omnibus repeated measures analysis of variance (rmANOVA), 18 performance measures (accuracy, mean response time) were $z$-standardized on mean and standard deviation at pretest across both age groups, and additionally the sign of the response time $z$ scores was inverted so that for all performance measures positive $z$ scores indicated training gains.

\section{EEG Data Acquisition}

EEG was recorded continuously with BrainAmp amplifiers (Brain Products $\mathrm{GmbH}$, Gilching, Germany) from $64 \mathrm{Ag} / \mathrm{AgCl}$ electrodes. Sixty scalp electrodes embedded in an elastic cap (EASYCAP $\mathrm{GmbH}$, Herrsching, Germany) were organized according to the $10 \%$ system (cf. Oostenveld \& Praamstra, 2001). Ground was placed at AFz. Two electrodes were placed on the outer canthi (horizontal electrooculogram [EOG]) and one electrode below the left eye (vertical EOG) in order to monitor eye movements. During recording, all electrodes were referenced to the right mastoid electrode, while the left mastoid electrode was recorded as an additional channel. Electrode impedances were maintained below $5 \mathrm{k} \Omega$ before recording. The EEG was recorded with an analog band-pass of 0.1 to $250 \mathrm{~Hz}$ and digitized with a sampling rate of $1 \mathrm{kHz}$. EEG resting state data were acquired from two conditions: 2 min of recording with eyes closed (EC) and 2 min of recording with eyes

Table 2. Average Training Gains in 12 Trained Cognitive Tasks from the Three Cognitive Domains: Perceptual Speed, Working Memory, and Episodic Memory

\begin{tabular}{|c|c|c|c|c|c|c|c|c|c|c|c|c|c|c|c|}
\hline & & & \multirow[b]{3}{*}{ Age group } & \multicolumn{5}{|c|}{ Intervention group } & \multicolumn{5}{|c|}{ Control group } & & \\
\hline & & & & \multicolumn{2}{|c|}{ Pretest } & \multicolumn{2}{|c|}{ Posttest } & \multirow[b]{2}{*}{ d } & \multicolumn{2}{|c|}{ Pretest } & \multicolumn{2}{|c|}{ Posttest } & \multirow[b]{2}{*}{$d$} & \multicolumn{2}{|c|}{ Time $\times$ Group } \\
\hline & & & & Mean & $S D$ & Mean & $S D$ & & Mean & $S D$ & Mean & $S D$ & & $F$ & $p$ \\
\hline \multirow[t]{12}{*}{ CRT } & NUM & $\mathrm{ACC}$ & YA & 0.92 & 0.05 & 0.89 & 0.08 & -0.64 & 0.90 & 0.05 & 0.92 & 0.06 & 0.21 & 4.74 & $<.05$ \\
\hline & & & OA & 0.82 & 0.06 & 0.92 & 0.05 & 1.70 & 0.79 & 0.09 & 0.81 & 0.10 & 0.23 & 24.08 & $<.001$ \\
\hline & & RT & YA & 536 & 81 & 353 & 58 & 2.26 & 550 & 73 & 495 & 77 & 0.75 & 29.70 & $<.001$ \\
\hline & & & $\mathrm{OA}$ & 621 & 169 & 482 & 86 & 0.82 & 629 & 144 & 565 & 129 & 0.44 & 3.92 & n.s. \\
\hline & VER & ACC & YA & 0.85 & 0.07 & 0.85 & 0.09 & -0.04 & 0.81 & 0.10 & 0.81 & 0.09 & 0.01 & 0.04 & n.s. \\
\hline & & & OA & 0.79 & 0.06 & 0.86 & 0.06 & 0.96 & 0.78 & 0.10 & 0.78 & 0.12 & 0.01 & 6.50 & $<.05$ \\
\hline & & RT & YA & 475 & 61 & 346 & 68 & 2.10 & 467 & 75 & 442 & 75 & 0.32 & 24.16 & $<.001$ \\
\hline & & & $\mathrm{OA}$ & 630 & 166 & 505 & 97 & 0.75 & 653 & 140 & 588 & 120 & 0.46 & 1.57 & n.s. \\
\hline & FIG & ACC & YA & 0.86 & 0.06 & 0.91 & 0.09 & 0.71 & 0.85 & 0.07 & 0.89 & 0.07 & 0.54 & 0.03 & n.s. \\
\hline & & & $\mathrm{OA}$ & 0.83 & 0.05 & 0.89 & 0.06 & 1.27 & 0.79 & 0.11 & 0.79 & 0.10 & -0.05 & 10.51 & $<.01$ \\
\hline & & RT & YA & 431 & 62 & 295 & 53 & 2.20 & 407 & 74 & 384 & 55 & 0.31 & 30.76 & $<.001$ \\
\hline & & & OA & 511 & 136 & 424 & 91 & 0.64 & 560 & 141 & 477 & 114 & 0.37 & 0.97 & n.s. \\
\hline \multirow[t]{12}{*}{ CT } & NUM & $\mathrm{ACC}$ & YA & 0.95 & 0.03 & 0.95 & 0.05 & 0.03 & 0.94 & 0.04 & 0.94 & 0.04 & 0.08 & 0.03 & n.s. \\
\hline & & & $\mathrm{OA}$ & 0.94 & 0.04 & 0.99 & 0.01 & 1.03 & 0.93 & 0.08 & 0.94 & 0.06 & 0.17 & 6.29 & $<.05$ \\
\hline & & RT & YA & 1474 & 229 & 1169 & 221 & 1.33 & 1456 & 163 & 1393 & 210 & 0.39 & 16.11 & $<.001$ \\
\hline & & & $\mathrm{OA}$ & 1807 & 265 & 1664 & 289 & 0.54 & 1774 & 277 & 1812 & 280 & -0.14 & 8.65 & $<.01$ \\
\hline & VER & $\mathrm{ACC}$ & YA & 0.93 & 0.04 & 0.94 & 0.06 & 0.18 & 0.91 & 0.04 & 0.92 & 0.05 & 0.05 & 0.08 & n.s. \\
\hline & & & OA & 0.87 & 0.07 & 0.95 & 0.03 & 1.28 & 0.90 & 0.05 & 0.89 & 0.07 & -0.14 & 30.70 & $<.001$ \\
\hline & & RT & YA & 1665 & 262 & 1312 & 254 & 1.34 & 1660 & 182 & 1568 & 219 & 0.51 & 11.11 & $<.01$ \\
\hline & & & $\mathrm{OA}$ & 2094 & 316 & 2044 & 319 & 0.16 & 2093 & 257 & 2128 & 233 & -0.14 & 1.37 & n.s. \\
\hline & FIG & $\mathrm{ACC}$ & YA & 0.90 & 0.06 & 0.91 & 0.10 & 0.19 & 0.90 & 0.05 & 0.89 & 0.08 & -0.29 & 1.37 & n.s. \\
\hline & & & $\mathrm{OA}$ & 0.83 & 0.06 & 0.93 & 0.07 & 1.73 & 0.81 & 0.08 & 0.84 & 0.07 & 0.31 & 10.32 & $<.01$ \\
\hline & & RT & YA & 2172 & 355 & 1238 & 288 & 2.63 & 2258 & 220 & 2022 & 378 & 1.07 & 44.30 & $<.001$ \\
\hline & & & OA & 2681 & 405 & 2266 & 448 & 1.02 & 2740 & 358 & 2794 & 208 & -0.15 & 8.42 & $<.01$ \\
\hline \multirow[t]{6}{*}{ WM } & NUM & $\mathrm{ACC}$ & YA & 0.65 & 0.10 & 0.82 & 0.09 & 1.77 & 0.62 & 0.11 & 0.66 & 0.09 & 0.38 & 37.59 & $<.001$ \\
\hline & & & $\mathrm{OA}$ & 0.54 & 0.14 & 0.74 & 0.08 & 1.35 & 0.52 & 0.15 & 0.53 & 0.16 & 0.10 & 25.70 & $<.001$ \\
\hline & VER & $\mathrm{ACC}$ & YA & 0.64 & 0.06 & 0.73 & 0.10 & 1.50 & 0.59 & 0.10 & 0.61 & 0.08 & 0.20 & 11.00 & $<.01$ \\
\hline & & & OA & 0.53 & 0.06 & 0.60 & 0.07 & 1.10 & 0.54 & 0.08 & 0.52 & 0.08 & -0.24 & 22.75 & $<.001$ \\
\hline & FIG & $\mathrm{ACC}$ & YA & 0.82 & 0.10 & 0.92 & 0.09 & 1.03 & 0.83 & 0.09 & 0.86 & 0.09 & 0.33 & 11.36 & $<.01$ \\
\hline & & & $\mathrm{OA}$ & 0.68 & 0.08 & 0.77 & 0.12 & 1.19 & 0.70 & 0.08 & 0.68 & 0.11 & -0.22 & 7.74 & $<.01$ \\
\hline \multirow[t]{6}{*}{ EM } & NUM & $\mathrm{ACC}$ & YA & 0.40 & 0.18 & 0.59 & 0.23 & 1.02 & 0.35 & 0.19 & 0.41 & 0.20 & 0.29 & 8.89 & $<.01$ \\
\hline & & & OA & 0.19 & 0.08 & 0.30 & 0.13 & 1.40 & 0.22 & 0.12 & 0.25 & 0.13 & 0.27 & 6.72 & $<.05$ \\
\hline & VER & $\mathrm{ACC}$ & YA & 0.35 & 0.15 & 0.58 & 0.18 & 1.58 & 0.32 & 0.18 & 0.41 & 0.19 & 0.47 & 12.38 & $<.01$ \\
\hline & & & $\mathrm{OA}$ & 0.19 & 0.06 & 0.32 & 0.14 & 2.26 & 0.18 & 0.06 & 0.23 & 0.08 & 0.84 & 6.22 & $<.05$ \\
\hline & FIG & ACC & YA & 0.44 & 0.14 & 0.58 & 0.20 & 1.01 & 0.37 & 0.16 & 0.39 & 0.17 & 0.08 & 9.38 & $<.01$ \\
\hline & & & OA & 0.32 & 0.16 & 0.45 & 0.15 & 0.79 & 0.36 & 0.14 & 0.39 & 0.12 & 0.18 & 7.01 & $<.05$ \\
\hline
\end{tabular}

Note. Time $\times$ Group $=$ interaction from $2 \times 2$ rmANOVAs with factors time (pretest, posttest) and group (intervention, control)—the interaction serves as an estimate for the reliability of the training effect beyond the effect of the repeated assessment of a task (see Schmiedek, Lövdén, \& Lindenberger, 2010). $\mathrm{CRT}=$ choice reaction time task; $\mathrm{CT}=$ comparison task; $\mathrm{WM}=$ working memory task; $\mathrm{EM}=$ episodic memory task; $\mathrm{NUM}=$ numerical stimulus material; $\mathrm{VER}=$ verbal stimulus material; FIG $=$ figural $/$ spatial stimulus material; RT $=$ response time in $\mathrm{ms} ; \mathrm{ACC}=$ accuracy; YA $=$ younger adults; OA $=$ older adults; $S D=$ standard deviation; $d=$ Cohen's $d ; n . s .=p>.05$. 
open (EO). Participants were instructed to sit as relaxed and still as possible and to fixate a fixation cross during the EO condition.

\section{EEG Data Preprocessing}

Preprocessing and analysis of EEG data was performed using the EEGLAB (Delorme \& Makeig, 2004) and FieldTrip (Oostenveld, Fries, Maris, \& Schoffelen, 2011) toolboxes, as well as customwritten MATLAB (The MathWorks Inc., Natick, MA) code. EEG data was rereferenced to mathematically linked mastoids, filtered with a 4th order Butterworth filter and a band-pass of 0.5 to $100 \mathrm{~Hz}$, and segmented into epochs of $1 \mathrm{~s}$. Segments were visually inspected, and all segments containing artifacts other than eye blinks and eye movements were excluded from further analyses. After manual artifact rejection, an independent component analysis (ICA; Bell \& Sejnowski, 1995) was conducted in order to correct for eye blinks and movements. Artifact corrected data was then subjected to a FFT within the FieldTrip toolbox, using a Hanning window and zero padding to $10 \mathrm{~s}$, in order to obtain a frequency resolution of $0.1 \mathrm{~Hz}$.

\section{Estimation of IAF and Alpha Amplitude}

IAF was estimated as peak alpha frequency from the mean spectrum over 17 posterior electrodes (Pz, P1/2, P3/4, P5/6, P7/8, POz, $\mathrm{PO} 3 / 4, \mathrm{PO} 7 / 8, \mathrm{Oz}$, and $\mathrm{O} 1 / 2$ ) by means of peak detection between 7.5 and $12.5 \mathrm{~Hz}$. IAF was estimated separately for the EC and EO condition, since both IAF measures can be found in the literature (e.g., McEvoy, Smith, \& Gevins, 2000). Peaks were defined as those frequency points where the first derivative of the spectrum changed from positive to negative. Searching explicitly for peaks (zero crossings of the first derivative) assured that we extracted true peaks from the spectrum rather than maximal values at the boundary of the predefined alpha range. For every participant, four IAF values were determined (IAF for EC and EO at pretest and posttest, respectively). In one out of 340 peak estimations ( $0.3 \%)$ only, no peak was found in the alpha range (EC pretest, male older adult, intervention group).

The focus of this article is on testing training-related changes in IAF. However, given that the amplitude of alpha oscillations was also repeatedly reported to demonstrate high stability in the presence of large interindividual differences (e.g., Burgess \& Gruzelier, 1993; Enoch et al., 2008; Gasser et al., 1985; Näpflin, Wildi, \& Sarnthein, 2007; Pollock, Schneider, \& Lyness, 1991; D. J. Smit et al., 2005), probably as a consequence of high heritability (e.g., Enoch et al., 2008; C. M. Smit et al., 2006; D. J. Smit et al., 2005; van Beijsterveldt \& van Baal, 2002; Vogel, 1970), we also conducted stability analyses on estimates of alpha amplitude. This set of analyses was primarily intended as a control for the validity of our methods. Alpha amplitude was defined as the mean amplitude of the frequency spectrum of the 17 posterior electrodes $\pm 1 \mathrm{~Hz}$ around the IAF. Here, we follow the convention of reporting amplitude of frequency bands within approximately $2 \mathrm{~Hz}$ bins (e.g., Babiloni, Frisoni et al., 2009; Doppelmayr et al., 1998; Klimesch, 1999). Statistical analyses were conducted on log-transformed amplitude values, as raw scores were not normally distributed. The grand average amplitude spectra at representative electrode positions as well as the topographical distribution of alpha amplitudes at IAF are shown in Figure 1.

\section{Statistical Analyses}

Statistical analyses were done in MATLAB (MathWorks) and SPSS 15.0 (SPSS Inc., Chicago, IL). Overall changes in cognitive performance were assessed by means of rmANOVA with the factors Time (pretest vs. posttest) $\times$ Age (younger vs. older adults $) \times$ Group (intervention vs. control group) $\times$ Task $(18$ performance scores from 12 tasks, see above). Whenever the assumption of sphericity was violated (Mauchly's test), Greenhouse-Geisser corrected degrees of freedom and $p$ values are reported. Specific effects of cognitive training are given as effect sizes $(d)$, calculated separately for younger and older adults as mean pretest versus posttest differences divided by the $S D$ at pretest. Statistical significance of effect sizes was investigated by testing the Time $\times$ Group interactions for each cognitive measure separately for both age groups. Overall changes in IAF and alpha amplitude due to cognitive training were assessed by rmANOVA with the factors Time $\times$ Age $\times$ Group $\times$ Condition (eyes closed vs. eyes open). To ensure that changes in IAF and alpha amplitude were not masked by the control group, one-sample Student's $t$ tests were conducted, and for each condition and age group the Time $\times$ Group interactions were tested for significance. Correlations between IAF and cognitive performance were estimated by Spearman correlation coefficients $(\rho)$; the sign of the correlation coefficients between IAF and mean response times was inverted, so that positive correlations indicate better performance being related to higher alpha frequencies. Within-session reliability and testretest stability were estimated with the Pearson correlation coefficient $(r)$, testing explicitly for a linear relationship between IAF measures. The reliability of IAF and alpha amplitude measures at pretest and posttest was assessed by means of an odd-even split of consecutive clean 1-s segments. Separate IAF and alpha amplitude values for the resulting two data halves were estimated as described above. Significant differences between correlation coefficients were assessed by means of Fisher's $Z$ transformation.

\section{Results}

\section{Illustration of Training Gains}

The intervention group in the EEG subsample showed reliable and large training effects in all 12 trained cognitive tasks (Table 2). The effects were comparable to those in the total COGITO sample (Schmiedek et al., 2010). At pretest, performance between the intervention and control group did not differ significantly, YA: all $t \mathrm{~s}(43)<1.85, p \mathrm{~s}>.05$; OA: all $t \mathrm{~s}(38)<1.45, p \mathrm{~s}>.05$.

Omnibus rmANOVA with factors Time (pretest vs. posttest) $\times$ Age (young vs. old) $\times$ Group (intervention vs. control) $\times$ Task (18 performance measures) revealed overall significant effects of time, $\quad F(1,81)=351.75, \quad p<.001 ; \quad$ age,$\quad F(1,81)=77.46$, $p<.001$; and group, $F(1,81)=21.58, p<.001$; but not of task, $F(6.22,497.46)=1.77, p>.05$. The Time $\times$ Group interaction was highly reliable, $F(1,81)=151.53, p<.001$, indicating a differential effect of training on cognitive performance in the intervention group. The Time $\times$ Age and Time $\times$ Group $\times$ Age interactions were not significant, $F_{\mathrm{s}}(1,81)<3.24$, $p \mathrm{~s}>.05$, pointing to comparable overall cognitive training effects in both age groups. On the other hand, the Time $\times$ Task, $F(8.95,716.12)=5.24, p<.001$; Age $\times$ Task, $F(6.22,497.46)=7.53, p<.001 ;$ Time $\times$ Age $\times$ Task, $F(8.95,716.12)=8.32, p<.001$; and Time $\times$ Age $\times$ Group $\times$ Task, $F(8.95,716.12)=3.60, p<.001$, interactions were highly reliable. As will be shown below, these interactions primarily reflect differential speed-accuracy trade-offs within the two age groups in the perceptual speed tasks.

The specific cognitive training gains in accuracy and mean response time within age groups and cognitive domains are sum- 


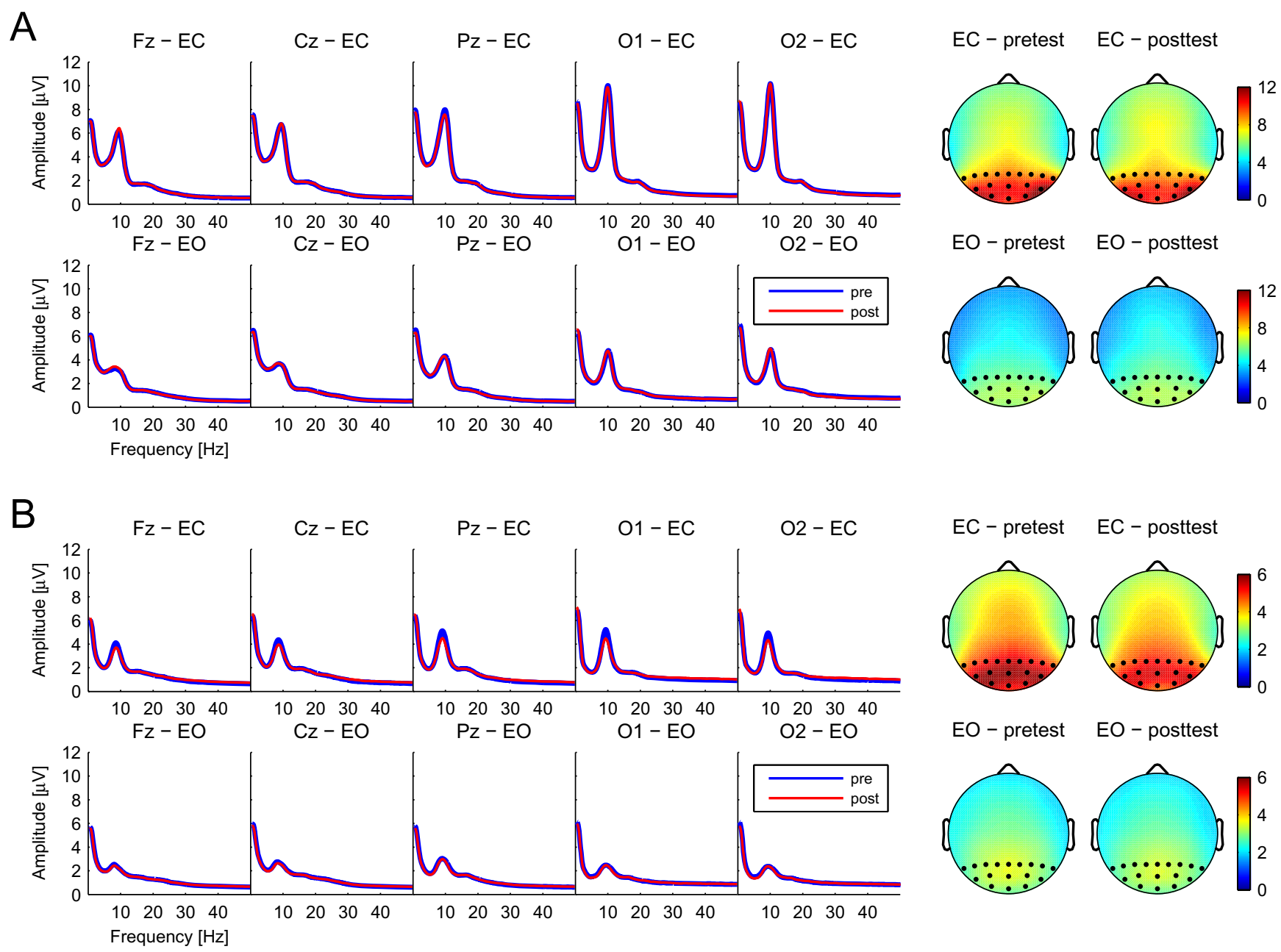

Figure 1. Grand average of the amplitude spectra at representative electrodes $\mathrm{Fz}, \mathrm{Cz}, \mathrm{Pz}, \mathrm{O} 1$, and $\mathrm{O} 2$. A: data from all younger adults $(N=45)$; B: data from all older adults $(N=40)$. Note that the spectra are highly self-similar, indicating high reliability of the spectra. On the right, the grand-average amplitude distribution at individual alpha frequency (IAF) $\pm 1 \mathrm{~Hz}$ is plotted across the scalp within each age group and condition. The amplitude is highest at occipital and parietal electrodes; black dots indicate electrode positions included in the calculation of IAF. Note the different scaling for the two age groups. EC $=$ eyes closed; $\mathrm{EO}=$ eyes open; pre $=$ pretest; post $=$ posttest.

marized in Table 2, together with the effect sizes $(d)$ and the Time $\times$ Group interaction serving as a test for statistical significance of training improvements beyond effects of repeated assessment. For the two perceptual speed tasks (CRT, CT), a differential speed-accuracy trade-off in performance gains was observed for the two age groups. Whereas the younger adults improved exclusively and strongly in their mean response times $(d=1.33$ to 2.63 with highly reliable Time $\times$ Group interactions), the older adults showed a larger and consistent improvement in their accuracies ( $d=0.96$ to 1.73 with highly reliable Time $\times$ Group interactions, except CRT verbal $p<.05)$ as compared to their mean response times ( $d=0.16$ to 1.02 , with only the interactions in the numerical and figural CT being highly reliable). Working memory and episodic memory improved considerably in both age groups (YA: $d=1.01$ to 1.77 , highly reliable Time $\times$ Group interactions; OA: $d=0.79$ to 2.26 , highly reliable Time $\times$ Group interactions in the WM tasks, reliable Time $\times$ Group interactions in the EM tasks). Taken together, large and reliable training-related performance gains were observed within the EEG subsample of the COGITO study.

\section{Stability of IAF: No Change Due to Extensive Cognitive Training}

In stark contrast to the behavioral findings, we found no reliable changes in mean IAF from pretest to posttest (Figure 2A and B). Overall rmANOVA on IAF with factors Time $\times$ Group $\times$ Condition (eyes closed vs. eyes open $) \times$ Age did not reveal any significant main effects or interactions, all $F \mathrm{~s}(1,80)<2.97$; $p \mathrm{~s}>.05$, except for the factor age, $F(1,80)=5.07, p<.05$, indicating slower IAF in older adults on average. The observed age group difference in IAF amounted to $0.49 \mathrm{~Hz}$ with eyes closed $(d=0.62)$ and $0.56 \mathrm{~Hz}$ with eyes open $(d=0.53)$. None of the $t$-test contrasts (pretest vs. posttest) within age groups and conditions indicated a reliable increase of IAF from pretest to posttest (all $t \mathrm{~s}<1.39, p \mathrm{~s}>.05$, effect sizes in the intervention group: $\mathrm{YA}_{\mathrm{EC}}: d=-0.08$; $\mathrm{YA}_{\mathrm{EO}}: d=-0.19$; $\mathrm{OA}_{\mathrm{EC}}$ : $d=0.15$; $\mathrm{OA}_{\mathrm{EO}}: 0.03$ ). Equally, none of the Time $\times$ Group interactions within age groups and conditions reached significance (all $F$ s $<2.64, p$ s $>.05$ ), showing that there were no differential effects of cognitive training on IAF in the experimental group as compared to the control group. Taken together, mean IAF was found to be 

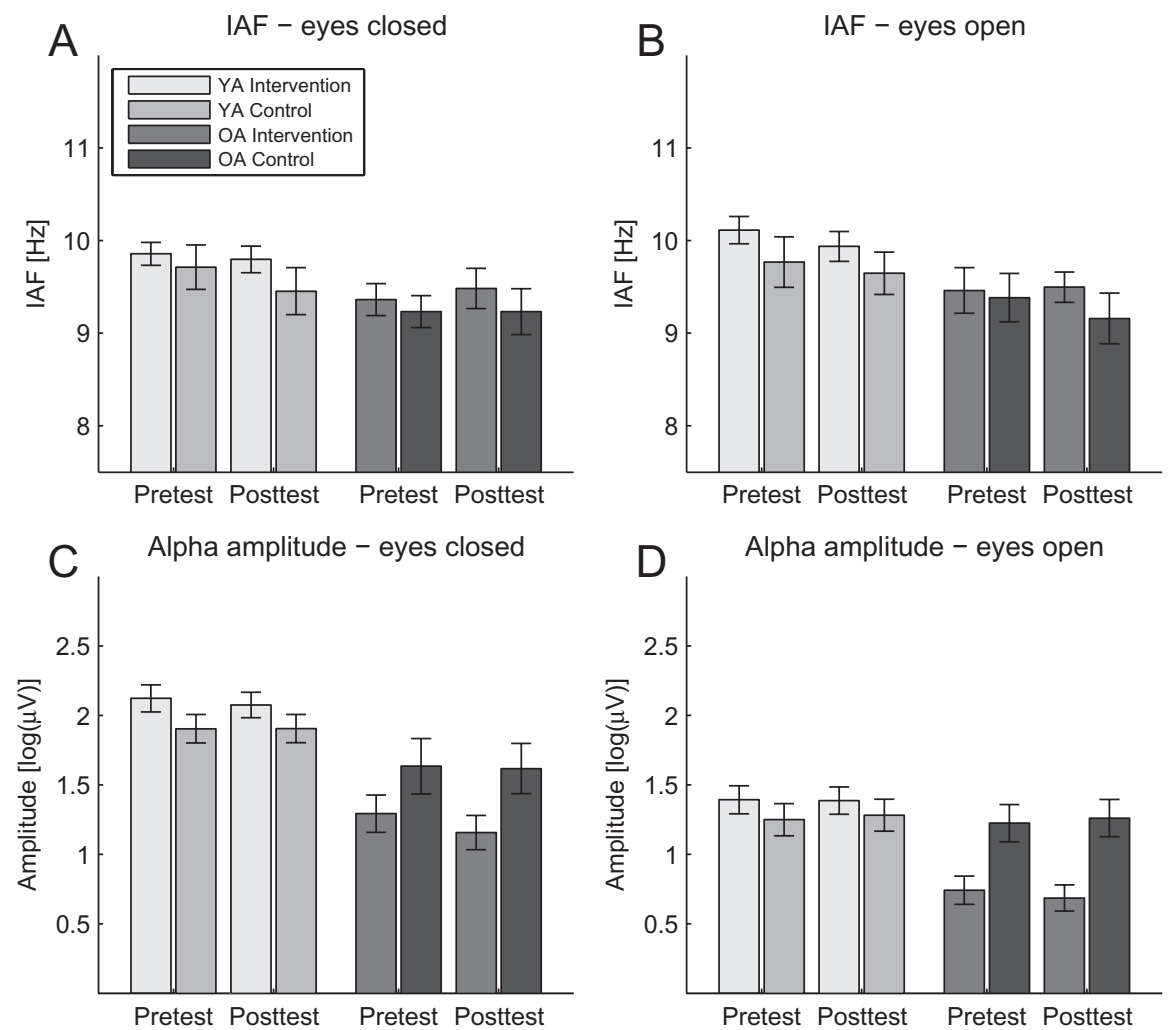

Figure 2. Average individual alpha frequency (IAF) and log-transformed alpha amplitude of the resting EEG with eyes closed and eyes open before and after extensive cognitive training. The mean amplitude was computed for $\pm 1 \mathrm{~Hz}$ around the IAF. None of the $t$-test contrasts indicated a significant increase in IAF or alpha amplitude as a function of cognitive training (IAF: all $t \mathrm{~s}<1.39, p \mathrm{~s}>.05$; amplitude: all $t \mathrm{~s}<1.10, p s>.05$ ). YA = younger adults; OA $=$ older adults; pre $=$ pretest; post $=$ posttest. Error bars represent the standard error of the mean $(S E)$.

stable in healthy younger and older adults over a period of 6.6 months. Notably, this result applied to a no-contact control group, and to an intervention group showing massive performance improvements on 12 trained tasks as well as small but reliable positive transfer effects at the level of broad cognitive abilities (see Schmiedek et al., 2010).

\section{Correlations Between IAF, Sample Descriptives, and Trained Tasks}

Given the substantial training-induced gains in behavioral performance and the apparent stability of mean IAF, one may wonder whether IAF was related to cognitive performance in the present sample in the first place. To test and confirm the functional significance of the IAF measure, we calculated correlation coefficients between IAF (eyes closed) and performance on cognitive tasks as assessed at pretest (Table 3).

For both age groups, a systematic but weak relationship between IAF and cognitive performance was observed. The average correlation coefficient across 20 individual coefficients was $\rho=.16$ for younger adults with 10 out of 20 coefficients significant at the .05 level, and $\rho=.14$ for older adults with 5 out of 20 coefficients significant at the .05 level. Note that under the validity of the null hypothesis, that is, the assumption that there is no association between IAF and cognition, spurious correlations should average out and $p$ values of correlation coefficients should be uniformly distributed. Thus, we tested the observed $p$ values for deviations from a uniform distribution by means of the Kolmogorov-Smirnov test. For both age groups, it indicated a highly reliable deviation from a uniform distribution (YA:
Table 3. Correlations ( $\rho)$ Between Individual Alpha Frequency (IAF) and Cognitive Performance at Pretest

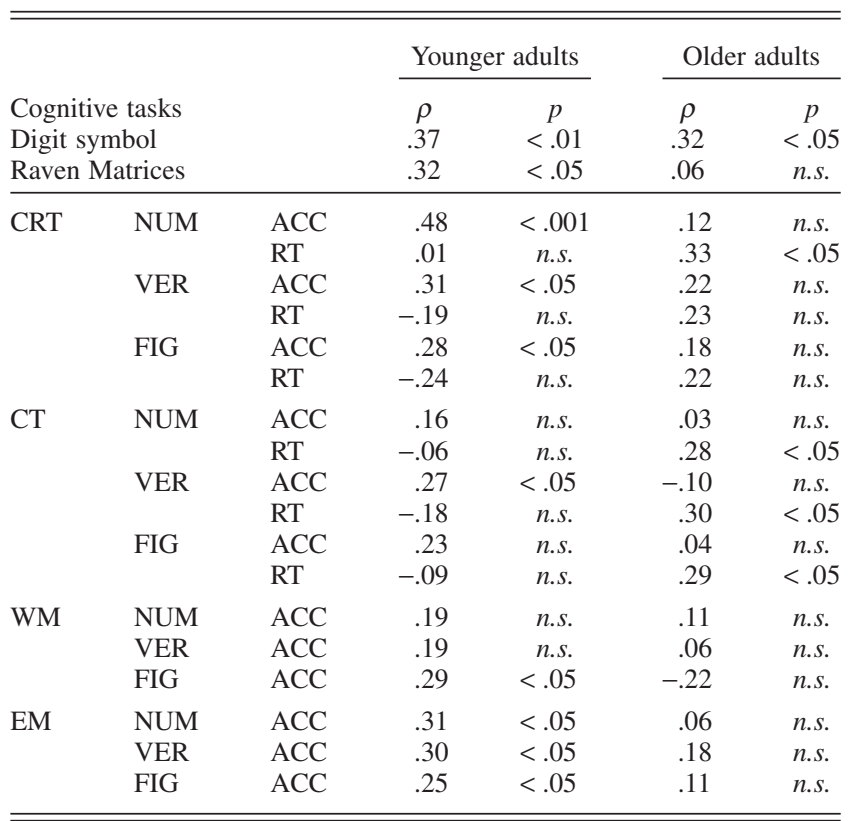

Note. For the correlation coefficients between IAF and RT, the sign was changed so that positive correlations indicate an association of higher IAF values with better cognitive performance. $\mathrm{CRT}=$ choice reaction time task; $\mathrm{CT}=$ comparison task $\mathrm{WM}=$ working memory; $\mathrm{EM}=$ episodic memory; $\mathrm{NUM}=$ numerical stimulus material; $\mathrm{VER}=$ verbal stimulus material; $\mathrm{FIG}=$ figural stimulus material; $\mathrm{ACC}=$ accuracy; $\mathrm{RT}=$ mean response time; n.s. $=p>.05$ 
A

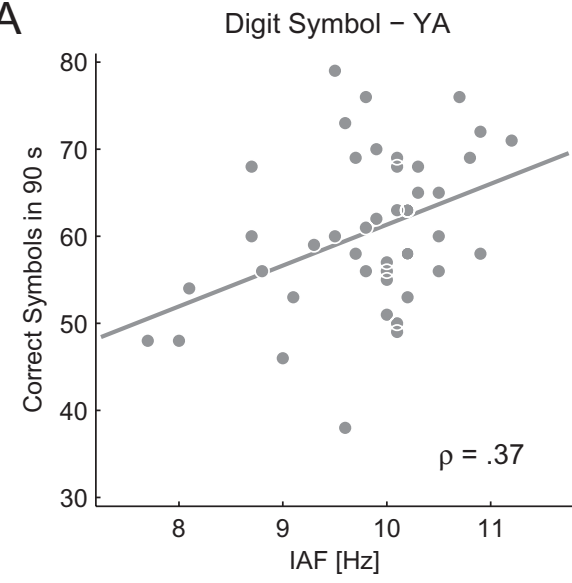

B

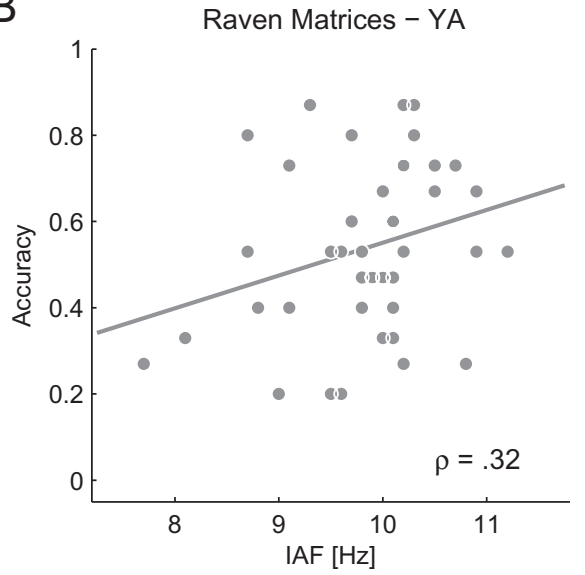

Digit Symbol - OA

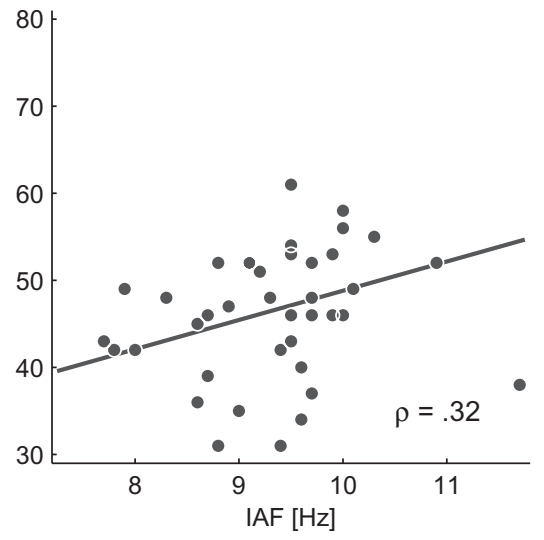

Raven Matrices - OA

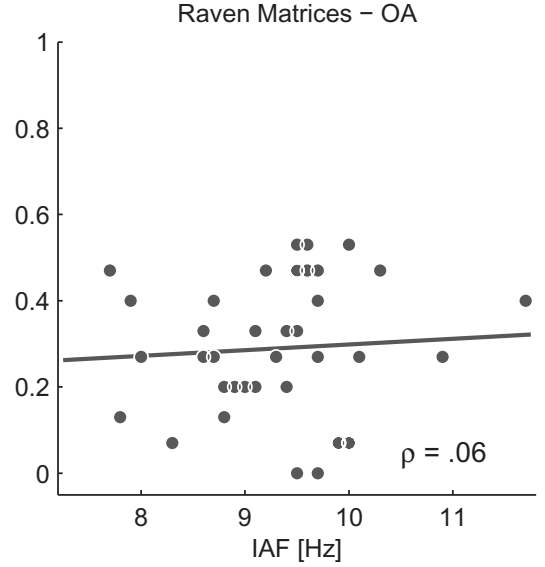

Figure 3. Relationship between IAF and cognitive performance for two exemplary tasks at pretest (A: Digit Symbol; B: Raven Matrices).

Kolmogorov-Smirnov $Z(20)=2.45, p<.001$; OA: KolmogorovSmirnov $Z(20)=1.94, p<.01)$, indicating that the observed pattern of correlation coefficients is unlikely under the assumption of no association between IAF and cognitive measures. Taken together, the positive relation between IAF at rest with eyes closed and cognition, albeit weak, appears to be systematic in our sample and replicates well earlier findings (cf. Anokhin and Vogel, 1996; Klimesch, 1996, 1997; Klimesch et al., 1996). Figure 3 provides scatter plots of IAF versus performance in the Digit Symbol substitution task and the Raven Matrices task, which represent well the overall picture of the relationship between IAF and cognitive performance in the current sample: whereas both age groups showed a weak positive relationship between IAF and speed tasks (CRT, CT, Digit Symbol), for the more complex tasks (WM, EM, Raven Matrices) only for the younger adults were substantial positive correlations observed.

\section{Reliability and Stability of Between-Person Differences in IAF}

Table 4 provides the split-half reliability coefficients for pretest and posttest as well as the test-retest stability coefficients of the IAF and alpha amplitude between pretest and posttest (see also Figure 4). The test-retest interval was on average 6.6 months $(S D=0.9)$.

At pretest, IAF for eyes closed was measured with high reliability (YA: $r>.94$; OA: $r>.83$; $p$ s $<.01$ ). Test-retest stability coefficients indicate that between-person differences in IAF with eyes closed were stable over time (YA: $r=.89$; OA: $r=.82$; $p$ s $<.01)$. Importantly, stability coefficients were only slightly lower than the corresponding reliability estimates, suggesting high stability of individual differences in IAF. In fact, when correcting the test-retest stabilities for attenuation due to unreliability of the measurements at pretest and posttest (cf. Spearman, 1904), we obtained test-retest stability estimates of $r=.93$ for younger and $r=.97$ for older adults. Thus IAF with eyes closed is highly reliable and stable with regard to the rank order of individuals across a test-retest interval of 6.6 months. IAF with eyes open was highly reliable for younger $(r=.89 ; p<.01)$ but not as reliable for older adults $(r=.72 ; p<.01)$. Furthermore IAF with eyes open was found to be highly stable within younger adults $(r=.88, p<.01)$, but less stable in the older adults group $(r=.61, p<.01)$. However, after correction for attenuation, stability estimates for eyes open reached the level estimated for the eyes closed condition (YA: $r=.97$; OA: $r=.90$ ).

Comparison of correlation coefficients by means of Fisher's $Z$ transformation revealed no significant differences between testretest stability coefficients of younger and older adults for IAF with eyes closed $(z \mathrm{~s}<1.91, p \mathrm{~s}>.05$, for empirical as well as corrected coefficients), but significant differences between the split-half reliabilities at pretest $(z>2.12, p<.05)$. In the eyes open condition, significantly lower stability as well as reliability coefficients for older as compared to younger adults were found $(z s>2.10$, $p s<.05)$. Furthermore, the correlation of IAF values aggregated over pretest and posttest for eyes closed with the corresponding 
Table 4. Measures of IAF Stability and Reliability

\begin{tabular}{|c|c|c|c|c|c|c|c|}
\hline Measure & Condition & $\begin{array}{l}\text { Age } \\
\text { group }\end{array}$ & $\begin{array}{l}\text { Experimental } \\
\text { group }\end{array}$ & $\begin{array}{l}\text { Test-retest } \\
\text { stability }(n)\end{array}$ & $\begin{array}{l}\text { Test-retest } \\
\text { stability }(n)\end{array}$ & $\begin{array}{l}\text { Split-half reliability } \\
\text { at pretest }(n)\end{array}$ & $\begin{array}{l}\text { Stability after correction } \\
\text { for attenuation }(n)\end{array}$ \\
\hline \multirow[t]{4}{*}{ IAF } & \multirow[t]{2}{*}{ Eyes closed } & Young & Intervention & $.91 * *(30)$ & $.89^{* *}(45)$ & $.94 * *(45)$ & $.93(45)$ \\
\hline & & Old & $\begin{array}{l}\text { Intervention } \\
\text { Control }\end{array}$ & $\begin{array}{l}.87 * *(15) \\
.82 * *(27) \\
81 * *(12)\end{array}$ & $.82 * *(39)$ & $.85 * *(39)$ & $.97(39)$ \\
\hline & \multirow[t]{2}{*}{ Eyes open } & Young & $\begin{array}{l}\text { Intervention } \\
\text { Control }\end{array}$ & $\begin{array}{l}.87 * *(30) \\
.90 * *(15)\end{array}$ & $.88 * *(45)$ & $.89 * *(45)$ & $.96(45)$ \\
\hline & & Old & $\begin{array}{l}\text { Intervention } \\
\text { Control }\end{array}$ & $\begin{array}{l}.64 * *(28) \\
.61 *(12)\end{array}$ & $.61 * *(40)$ & $.72 * *(40)$ & $.90(40)$ \\
\hline \multirow[t]{4}{*}{ Alpha amplitude } & \multirow[t]{2}{*}{ Eyes closed } & Young & $\begin{array}{l}\text { Intervention } \\
\text { Control }\end{array}$ & $\begin{array}{l}.96 * *(30) \\
.89 * *(15)\end{array}$ & $.95^{* *}(45)$ & $.99 * *(45)$ & $.95(45)$ \\
\hline & & Old & $\begin{array}{l}\text { Intervention } \\
\text { Control }\end{array}$ & $\begin{array}{l}.91 * *(27) \\
.96 * *(12)\end{array}$ & $.93 * *(39)$ & $.99 * *(39)$ & $.94(39)$ \\
\hline & \multirow[t]{2}{*}{ Eyes open } & Young & $\begin{array}{l}\text { Intervention } \\
\text { Control }\end{array}$ & $\begin{array}{l}.91 * *(30) \\
.88 * *(15)\end{array}$ & $.90 * *(45)$ & $.98 * *(45)$ & $.92(45)$ \\
\hline & & Old & $\begin{array}{l}\text { Intervention } \\
\text { Control }\end{array}$ & $\begin{array}{r}.92 * *(28) \\
.9 * *(12)\end{array}$ & $.94 * *(40)$ & $.99 * *(40)$ & $.95(40)$ \\
\hline
\end{tabular}

$\overline{\text { Note. The intervention and control group as independent samples show very similar correlation coefficients. Mean temporal interval between pretest and }}$ posttest was 6.6 months.

$* p<.05 . * * p<.01$.
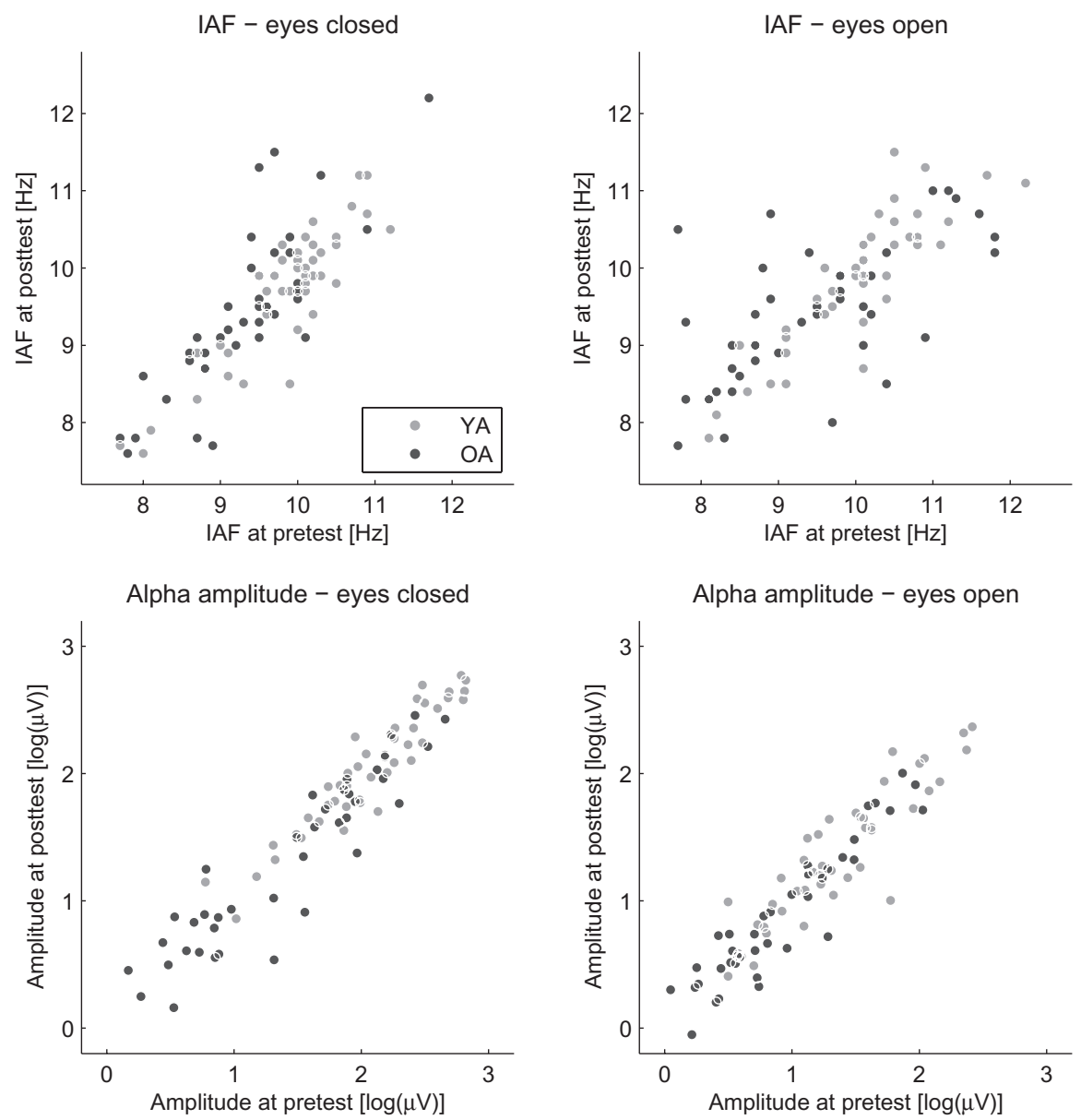

Figure 4. Scatter plots of individual alpha frequencies (IAF) and alpha amplitudes around IAF at pretest versus posttest as estimated from the resting EEG with eyes closed and eyes open. It can be seen that older adults show comparable stability when IAF is estimated from the resting EEG with eyes closed, but only exhibit moderate stability when the IAF is estimated from the eyes open condition. High stability of alpha amplitude was observed for both age groups and conditions. $\mathrm{YA}=$ younger adults; $\mathrm{OA}=$ older adults. 
aggregate for eyes open was high among younger adults $(r=.87$, $p<.01)$, and moderate among older adults $(r=.52, p<.01)$; the difference between the two correlations was reliable $(z>3.36$, $p<.01)$.

\section{Control Analysis: Stability of the Alpha Amplitude}

As discussed above, in the light of high stability of interindividual differences in alpha amplitude (Burgess \& Gruzelier, 1993; Enoch et al., 2008; Gasser et al., 1985; Näpflin et al., 2007; Pollock et al., 1991; D. J. Smit et al., 2005) and high heritability (Enoch et al., 2008; C. M. Smit et al., 2006; D. J. Smit et al., 2005; van Beijsterveldt \& van Baal, 2002; Vogel, 1970), we also conducted stability analyses on estimates of alpha amplitude. Overall, the analyses of amplitude estimates for alpha oscillations resembled the patterns observed for IAF. The split-half reliabilities for alpha amplitudes were close to perfect $(r=.98$ to $.99, p$ s $<.01)$. In addition, test-retest stability coefficients indicate that between-person differences in alpha amplitude at rest with eyes closed as well as eyes open were highly stable across a test-retest interval of 6.6 months (YA: $r=.95$ and .90; OA: $r=.93$ and .94; $p$ s <.01), well in line with the literature. Comparisons between reliability and stability coefficients for alpha amplitude did not reveal any significant differences between coefficients within and across experimental and age groups (all $z \mathrm{~s}<1.29, p \mathrm{~s}>.05$ ), indicating an overall high level of reliability and stability. Comparable to the IAF, also the mean alpha amplitude did not change reliably from pretest to posttest (Figure 2C and D). Overall, rmANOVA on the alpha amplitude with factors Time $\times$ Group $\times$ Condition $\times$ Age did not reveal significant main effects or interactions (all $F \mathrm{~s}(1,80)<2.98$; $p s>.05)$ with the following exceptions: highly reliable differences between the eyes closed and eyes open condition, $F(1,80)=$ $163.94 ; p<.001 ; d_{\mathrm{YA}}=1.34, d_{\mathrm{OA}}=0.77$, and between age groups, $F(1,80)=14.93 ; p<.001 ; d_{\mathrm{EC}}=1.15, d_{\mathrm{EO}}=0.89$, as well as a reliable Age $\times$ Condition, $F(1,80)=7.64 ; p<.01$, and Age $\times$ Group interactions, $F(1,80)=6.52 ; p<.05$. Also, for the alpha amplitude, no reliable increases from pretest to posttest were found (all $t \mathrm{~s}<1.10, p \mathrm{~s}>.05$, effect sizes in the intervention group: $\mathrm{YA}_{\mathrm{EC}}$ : $d=-0.10$; $\mathrm{YA}_{\mathrm{EO}}: d=-0.01$; $\mathrm{OA}_{\mathrm{EC}}: d=-0.19$; $\left.\mathrm{OA}_{\mathrm{EO}}:-0.10\right)$, and none of the Time $\times$ Group interactions within age groups and conditions reached significance (all $F \mathrm{~s}<1.99, p \mathrm{~s}>.05$ ).

\section{Discussion}

Following up on earlier work, this study closely examined the status of IAF as a neurophysiological trait marker. Several previous studies have reported stable individual differences in IAF (e.g., Kondacs \& Szabó, 1999; Salinsky et al., 1991) as well as betweenperson correlations between IAF and measures of cognitive abilities (e.g., Angelakis, Lubar, \& Stathopoulou, 2004; Anokhin \& Vogel, 1996; Klimesch, 1997; Mundy-Castle, 1958), suggesting a link between IAF and cognitive functioning. We confirmed observations of stable individual differences in IAF over a test-retest interval of about 6 months, and of weak but systematic positive correlations between IAF and cognitive performance. At the same time, we observed substantial training-related behavioral gains in several domains of cognition, including cognitive tasks in which performance was positively correlated with IAF at pretest. Nevertheless, mean IAF remained stable from pretest to posttest, confirming another important aspect of stability of IAF: the stability of absolute IAF values. Equally, in a control analysis alpha amplitude was shown to be stable across the test-retest interval of about 6 months. Between-person stability as well as stability of absolute values of IAF and alpha amplitude persisted into old age (65-80 years); thus far, complete evidence for this age period is not available. Age differences were observed with respect to the mean IAF and alpha amplitude as well as for reliability and stability of IAF as assessed with eyes open. We discuss these findings below, and argue that they are consistent with the notion that IAF (with eyes closed) qualifies as an individual neurophysiological trait marker that reflects general CNS functioning. Because it is relatively easy to assess, it has high potential for monitoring within-person changes of neurophysiological integrity up to old age.

\section{Age-Related IAF Slowing and the Reliability and Stability of IAF}

In line with previous reports (Aurlien et al., 2004; Chiang et al., 2011; Duffy, Albert, McAnulty, \& Garvey, 1984; Duffy, McAnulty, \& Albert, 1993), we observed that mean IAF is lower in older adults relative to younger adults. Reasons for the slowing of alpha frequency with advancing age may be found in age-related neuroanatomical changes, such as losses in gray matter volume, white matter integrity (cf. Raz, Ghisletta, Rodrigue, Kennedy, \& Lindenberger, 2010; Raz et al., 2005, 2012), and neurotransmitters (e.g., Bäckman, Lindenberger, Li, \& Nyberg, 2010). Theoretical models suggesting that properties of thalamocortical feedback loops may account for differences in IAF (David \& Friston, 2003; Jirsa, 2009; Lopes da Silva, 1991; Robinson et al., 2003) point to alterations in white matter microarchitecture as one potential determinant of individual differences and age-related changes in IAF. Recent empirical observations linking between-person differences in IAF to differences in white matter density (e.g., Valdes-Hernandez et al., 2010) and to white matter integrity (e.g., Babiloni et al., 2010) support this claim.

For IAF assessed with eyes closed, the within-session reliability and test-retest stability for an interval of 6.6 months are comparable to published data without intervening cognitive training (Deakin \& Exley, 1979; Gasser et al., 1985; Kondacs \& Szabó, 1999; Salinsky et al., 1991). For both age groups, we observed high reliability of the measurements as well as high stability of individual differences over time.

We also examined the reliability and stability of peak IAF in the resting EEG with eyes open, which to the best of our knowledge has not yet been reported explicitly (but see Doppelmayr et al., 1998; McEvoy et al., 2000; Näpflin et al., 2007; Näpflin, Wildi, \& Sarnthein, 2008). Younger adults exhibited a similar high reliability and stability of IAF with eyes open as with eyes closed, and the two IAF measures were found to correlate strongly. Among older adults, the reliability and stability for IAF with eyes open was significantly smaller, which also explains the smaller correlation between IAF with eyes closed and eyes open in that age group. Thus, for older adults IAF assessed with eyes open may only be of limited value as an individual neurophysiological marker.

\section{Extensive Cognitive Training Does Not Alter IAF}

IAF did not change as a result of extensive cognitive training, despite large behavioral training gains (average $d$ across 18 performance measures: $d_{\mathrm{YA}}=1.13, d_{\mathrm{OA}}=1.11$ ) in three different $\operatorname{cog}$ nitive domains, and despite weak but systematic correlations of IAF with cognitive performance in the present sample at pretest. Given the high reliability of IAF, the lack of change in IAF is unlikely to reflect measurement error. 
Correlations between IAF and cognitive performance at pretest indicate that cognitive training included tasks that are related to IAF. The observed pattern is consistent with the literature reporting correlations between IAF and cognitive performance in a very broad and diverse range of cognitive tasks (Angelakis, Lubar, \& Stathopoulou, 2004; Angelakis, Lubar, Stathopoulou \& Kounios, 2004; Anokhin \& Vogel, 1996; Clark et al., 2004; Giannitrapani, 1985; Klimesch et al., 1990, 1993; Mundy-Castle, 1958; Mundy-Castle \& Nelson, 1960; Surwillo, 1961, 1963). This makes it likely that IAF reflects general functional properties of the CNS (cf. Valdes-Hernandez et al., 2010), which is in line with more recent theoretical work suggesting that alpha oscillations are functionally related to gating of neural activity (cf. Jensen \& Mazaheri, 2010) and the provision of time frames for efficient neural communication (Klimesch et al., 2007; Mazaheri \& Jensen, 2010) rather than to specific task-related functions. From this perspective, the stability of IAF despite large intervention-related changes in cognitive performance reveals an important dissociation in the relation between IAF and cognition. It renders a reciprocal (causal) relationship between IAF and cognition underlying the correlation between IAF and cognitive performance highly unlikely, and rather supports the notion that IAF reflects stable general functional properties of the CNS that influence individual differences in cognition in a more indirect manner. In this sense, we argue that, within healthy adults up to 80 years, IAF is a highly stable individual systems marker of CNS functioning, hence qualifies as a neurophysiological trait marker.

Given that IAF was not influenced by substantial changes in cognitive performance, one may ask for the locus of the substantial performance gains due to extensive cognitive training. Generally, it follows that training leads to changes in the nervous system that does not directly alter IAF. Theoretical (David \& Friston, 2003; Jirsa, 2009; Lopes da Silva, 1991; Robinson et al., 2003) and empirical (Valdes-Hernandez et al., 2010) work points to posterior fiber tracts as one determining source of individual differences in IAF. Accordingly, it fits the picture that, within the COGITO study, training-related changes in white matter microstructure were restricted to the most anterior subsegment of the anterior corpus callosum (Lövdén et al., 2010), but not found in posterior fiber tracts, such as the forceps major, which have been shown to be related to IAF (Valdes-Hernandez et al., 2010). Thus, we do not imply that the cognitive training intervention did not induce any neurophysiological changes. Rather, it appears that some neurophysiological parameters related to cognitive performance in typical one-shot measurements, as demonstrated for the pretest data in the present report, are actually highly stable and may not be easily modifiable by cognitive interventions.

In line with previous observations, interindividual differences in alpha amplitude were also found to be highly reliable and stable (Enoch et al., 2008; Gasser et al., 1985; Kondacs \& Szabó, 1999; McEvoy et al., 2000; Pollock et al., 1991; Salinsky et al., 1991; D. J. Smit et al., 2005). Furthermore, mean alpha amplitude was highly stable across 6 months in both age groups, with lower absolute alpha amplitude in older adults (cf. Klimesch, 1999; Markand, 1990).

Taken together, the presented findings also provide an important complement to the literature reporting high heritability of parameters of the EEG, including IAF and alpha amplitude (e.g., Enoch et al., 2008; C. M. Smit et al., 2006; D. J. Smit et al., 2005; van Beijsterveldt \& van Baal, 2002; Vogel, 1970). By showing that IAF and alpha amplitude are highly stable even in the light of a largescale cognitive intervention, they support the notion that these parameters are under strong genetic control and as a consequence are not easily modifiable by environmental factors (cf. C. M. Smit et al., 2006). On the other hand this also implies that substantial changes in these parameters can be highly indicative of pathological processes (cf. Babiloni et al., 2008; Babiloni, Pievani et al., 2009; Moretti et al., 2004, 2007; Vogel, 1970).

\section{Interpretation and Conclusion}

The pattern of results observed in this study has important implications. The findings strongly suggest that IAF stability over time is an important characteristic of intact general CNS functioning. Absolute alpha frequency values per se may possess poor sensitivity and specificity as a clinical marker, but IAF may constitute a robust and easy-to-assess candidate for monitoring deviations from normal CNS functioning, such as progression of disease, by following within-person changes in IAF over time.

As an empirical method, EEG is easily applicable to assess functional aspects of the nervous system. It also comes with the advantage of measuring signals directly related to neural activity. Thus, it may add important diagnostic information to neuroimaging data that provide anatomical-structural information (e.g., Frisoni, Fox, Jack, Scheltens, \& Thompson, 2010) or more indirect measures of neural activity such as the blood oxygen level dependent (BOLD) signal. At the same time, EEG signals show large and often highly stable interindividual differences in various aspects (e.g., evoked potentials, frequency spectra, and their topographical distribution; cf. Burgess \& Gruzelier, 1993; Näpflin et al., 2007, 2008; Sarnthein, Andersson, Zimmermann, \& Zumsteg, 2009; Tuladhar et al., 2007; Van Dis, Corner, Dapper, Hanewald, \& Kok, 1979) that are also known to exhibit remarkably high heritability (Anokhin et al., 2001, 2006; Enoch et al., 2008; C. M. Smit et al., 2006; D. J. Smit et al., 2005; D. J. Smit, Stam, Posthuma, Boomsma, \& de Geus, 2008; D. J. A. Smit, Boomsma, Schnack, Hulshoff Pol, \& de Geus, 2012; van Beijsterveldt \& van Baal, 2002; Vogel, 1970). These interindividual differences may often go unnoticed in studies that focus exclusively on experimental or quasi-experimental comparisons at the group level.

We have shown that IAF is broadly distributed in the frequency spectrum (approximately 8-12 Hz) across persons, but extraordinarily stable within persons across 6 months, and in the presence of a massive cognitive intervention. Hence, it is worth exploring whether monitoring deviations from absolute stability in IAF within individuals may serve, for example, as a clinically relevant early sign of neuropathology. This perspective is somewhat similar to monitoring progression of disease in cancer patients, where a variety of cancer markers are monitored in relation to changes in their concentration at the individual level.

Another important implication of the present study relates to basic research concerning the neural underpinnings of cognition. There is currently a large interest in relating individual differences in neuroanatomy as well as neural functioning to individual differences in cognition (e.g., Deary, Penke, \& Johnson, 2010; Kanai \& Rees, 2011). The dissociation of two correlated variables with respect to changes in one of the two variables not necessarily being paralleled by changes in the other variable, as demonstrated here with cognitive performance and IAF, adds important information to the understanding of the directionality and causality of the relationship between indicators of neural and cognitive functioning. In this context, future studies should explore whether other forms of intervention are more effective in altering both cognition and IAF, and, if so, which mechanisms are driving the association between the two. 
To conclude, we propose that an explicit focus on the assessment of longitudinal change within healthy individuals or patients may help to better understand the associations between neurophysiological markers, such as IAF, and CNS functioning as well as (patho)physiological changes therein. Accordingly, future research with extended longitudinal designs and multimodal assessments (i.e., EEG, fMRI, diffusion tensor imaging, genomic imaging, etc.) is needed to delineate the mechanisms that underlie the complex relationship between the many levels of CNS functioning and cognition.

\section{References}

Angelakis, E., Lubar, J. F., \& Stathopoulou, S. (2004). Electroencephalographic peak alpha frequency correlates of cognitive traits. Neuroscience Letters, 371, 60-63.

Angelakis, E., Lubar, J. F., Stathopoulou, S., \& Kounios, J. (2004). Peak alpha frequency: An electroencephalographic measure of cognitive preparedness. Clinical Neurophysiology, 115, 887-897.

Anokhin, A. P., Müller, V., Lindenberger, U., Heath, A. C., \& Myers, E. (2006). Genetic influences on dynamic complexity of brain oscillations. Neuroscience Letters, 397, 93-98.

Anokhin, A. P., van Baal, G. C., van Beijsterveldt, C. E., de Geus, E. J., Grant, J., \& Boomsma, D. I. (2001). Genetic correlation between the P300 event-related brain potential and the EEG power spectrum. Behavior Genetics, 31, 545-554.

Anokhin, A. P., \& Vogel, F. (1996). EEG alpha rhythm frequency and intelligence in normal adults. Intelligence, 23, 1-14.

Aurlien, H., Gjerde, I. O., Aarseth, J. H., Eldoen, G., Karlsen, B., Skeidsvoll, H., \& Gilhus, N. E. (2004). EEG background activity described by a large computerized database. Clinical Neurophysiology, 115, 665673.

Babiloni, C., Frisoni, G. B., Pievani, M., Toscano, L., Del Percio, C., Geroldi, C., ... Rossini, P. M. (2008). White-matter vascular lesions correlate with alpha EEG sources in mild cognitive impairment. Neuropsychologia, 46, 1707-1720.

Babiloni, C., Frisoni, G. B., Pievani, M., Vecchio, F., Lizio, R., Buttiglione, M., . . Rossini, P. M. (2009). Hippocampal volume and cortical sources of EEG alpha rhythms in mild cognitive impairment and Alzheimer disease. Neuroimage, 44, 123-135.

Babiloni, C., Frisoni, G. B., Vecchio, F., Pievani, M., Geroldi, C., De Carli, C., . . Rossini, P. M. (2010). Global functional coupling of resting EEG rhythms is related to white-matter lesions along the cholinergic tracts in subjects with amnesic mild cognitive impairment. Journal of Alzheimer's Disease, 19, 859-871.

Babiloni, C., Pievani, M., Vecchio, F., Geroldi, C., Eusebi, F., Fracassi, C., ... Frisoni, G. B. (2009). White-matter lesions along the cholinergic tracts are related to cortical sources of EEG rhythms in amnesic mild cognitive impairment. Human Brain Mapping, 30, 1431-1443.

Bäckman, L., Lindenberger, U., Li, S.-C., \& Nyberg, L. (2010). Linking cognitive aging to alterations in dopamine neurotransmitter functioning: Recent data and future avenues. Neuroscience \& Biobehavioral Reviews, 34, 670-677.

Bell, A. J., \& Sejnowski, T. J. (1995). An information-maximization approach to blind separation and blind deconvolution. Neural Computation, 7, 1129-1159.

Berger, H. (1929). Über das Elektrenkephalogramm des Menschen [About the human electroencephalogram]. Archiv fur Psychiatrie und Nervenkrankheiten, 87, 527-570.

Berger, H. (1933). Über das Elektrenkephalogramm des Menschen V. [About the human electroencephalogram. Part V]. Archiv fur Psychiatrie und Nervenkrankheiten, 98, 231-254.

Burgess, A., \& Gruzelier, J. (1993). Individual reliability of amplitude distribution in topographical mapping of EEG. Electroencephalography and Clinical Neurophysiology, 86, 219-223.

Cantero, J. L., Atienza, M., Gomez-Herrero, G., Cruz-Vadell, A., GilNeciga, E., Rodriguez-Romero, R., . . . Garcia-Solis, D. (2009). Functional integrity of thalamocortical circuits differentiates normal aging from mild cognitive impairment. Human Brain Mapping, 30, 39443957.

Chiang, A. K., Rennie, C. J., Robinson, P. A., van Albada, S. J., \& Kerr, C. C. (2011). Age trends and sex differences of alpha rhythms including split alpha peaks. Clinical Neurophysiology, 122, 1505-1517.

Clark, C. R., Veltmeyer, M. D., Hamilton, R. J., Simms, E., Paul, R., Hermens, D., . . Gordon, E. (2004). Spontaneous alpha peak frequency predicts working memory performance across the age span. International Journal of Psychophysiology, 53, 1-9.

David, O., \& Friston, K. J. (2003). A neural mass model for MEG/EEG: Coupling and neuronal dynamics. Neuroimage, 20, 1743-1755.
Deakin, J. F. W., \& Exley, K. A. (1979). Personality and male-female influences on the EEG alpha rhythm. Biological Psychology, 8, 285290

Deary, I. J., Penke, L., \& Johnson, W. (2010). The neuroscience of human intelligence differences. Nature Reviews Neuroscience, 11, 201211

Delorme, A., \& Makeig, S. (2004). EEGLAB: An open source toolbox for analysis of single-trial EEG dynamics including independent component analysis. Journal of Neuroscience Methods, 134, 9-21.

d'Onofrio, F., Salvia, S., Petretta, V., Bonavita, V., Rodriguez, G., \& Tedeschi, G. (1996). Quantified-EEG in normal aging and dementias. Acta Neurologica Scandinavica, 93, 336-345.

Doppelmayr, M., Klimesch, W., Pachinger, T., \& Ripper, B. (1998). Individual differences in brain dynamics: Important implications for the calculation of event-related band power. Biological Cybernetics, 79, $49-57$.

Duffy, F. H., Albert, M. S., McAnulty, G., \& Garvey, A. J. (1984). Agerelated differences in brain electrical activity of healthy subjects. Annals of Neurology, 16, 430-438.

Duffy, F. H., McAnulty, G. B., \& Albert, M. S. (1993). The pattern of age-related differences in electrophysiological activity of healthy males and females. Neurobiology of Aging, 14, 73-84.

Enoch, M.-A., Shen, P.-H., Ducci, F., Yuan, Q., Liu, J., White, K. V., . . . Goldman, D. (2008). Common genetic origins for EEG, alcoholism and anxiety: The role of CRH-BP. PLOS ONE, 3, e3620.

Folstein, M. F., Folstein, S. E., \& McHugh, P. R. (1975). "Mini-mental state." A practical method for grading the cognitive state of patients for the clinician. Journal of Psychiatric Research, 12, 189-198.

Frisoni, G. B., Fox, N. C., Jack, C. R., Scheltens, P., \& Thompson, P. M. (2010). The clinical use of structural MRI in Alzheimer disease. Nature Reviews Neurology, 6, 67-77.

Gasser, T., Bächer, P., \& Steinberg, H. (1985). Test-retest reliability of spectral parameters of the EEG. Electroencephalography and Clinical Neurophysiology, 60, 312-319.

Gawel, M., Zalewska, E., Szmidt-Salkowska, E., \& Kowalski, J. (2007). Does EEG (visual and quantitative) reflect mental impairment in subcortical vascular dementia? Journal of the Neurological Sciences, 257, $11-16$.

Gawel, M., Zalewska, E., Szmidt-Salkowska, E., \& Kowalski, J. (2009). The value of quantitative EEG in differential diagnosis of Alzheimer's disease and subcortical vascular dementia. Journal of the Neurological Sciences, 283, 127-133.

Giannitrapani, D. (1985). The electrophysiology of intellectual functions. Basel, Switzerland: Karger.

Jelic, V., Johansson, S. E., Almkvist, O., Shigeta, M., Julin, P., Nordberg, A., ... Wahlund, L. O. (2000). Quantitative electroencephalography in mild cognitive impairment: Longitudinal changes and possible prediction of Alzheimer's disease. Neurobiology of Aging, 21, 533540.

Jensen, O., \& Mazaheri, A. (2010). Shaping functional architecture by oscillatory alpha activity: Gating by inhibition. Frontiers in Human Neuroscience, 4, 186.

Jirsa, V. K. (2009). Neural field dynamics with local and global connectivity and time delay. Philosophical Transactions of the Royal Society London, Series A (Mathematical, Physical \& Engineering Sciences), 367, 1131-1143.

Kagan, J. (1980). Perspectives on continuity. In O. G. Brim Jr. \& J. Kagan (Eds.), Constancy and change in human development (pp. 26-74). Cambridge, MA: Harvard University Press.

Kanai, R., \& Rees, G. (2011). The structural basis of inter-individual differences in human behaviour and cognition. Nature Reviews Neuroscience, 12, 231-242.

Klimesch, W. (1996). Memory processes, brain oscillations and EEG synchronization. International Journal of Psychophysiology, 24, 61-100.

Klimesch, W. (1997). EEG-alpha rhythms and memory processes. International Journal of Psychophysiology, 26, 319-340. 
Klimesch, W. (1999). EEG alpha and theta oscillations reflect cognitive and memory performance: A review and analysis. Brain Research-Brain Research Reviews, 29, 169-195.

Klimesch, W., Doppelmayr, M., Schimke, H., \& Pachinger, T. (1996). Alpha frequency, reaction time, and the speed of processing information. Journal of Clinical Neurophysiology, 13, 511-518.

Klimesch, W., Sauseng, P., \& Hanslmayr, S. (2007). EEG alpha oscillations: The inhibition-timing hypothesis. Brain Research Reviews, 53, $63-88$.

Klimesch, W., Schimke, H., Ladurner, G., \& Pfurtscheller, G. (1990). Alpha frequency and memory performance. Journal of Psychophysiology, 4, 381-390.

Klimesch, W., Schimke, H., \& Pfurtscheller, G. (1993). Alpha frequency, cognitive load and memory performance. Brain Topography, 5, 241-251.

Kondacs, A., \& Szabó, M. (1999). Long-term intra-individual variability of the background EEG in normals. Clinical Neurophysiology, 110, 17081716.

Lopes da Silva, F. H. (1991). Neural mechanisms underlying brain waves: From neural membranes to networks. Electroencephalography \& Clinical Neurophysiology, 79, 81-93.

Lövdén, M., Bodammer, N. C., Kuhn, S., Kaufmann, J., Schutze, H., Tempelmann, C., ... Lindenberger, U. (2010). Experience-dependent plasticity of white-matter microstructure extends into old age. Neuropsychologia, 48, 3878-3883.

Markand, O. N. (1990). Alpha rhythms. Journal of Clinical Neurophysiology, 7, 163-189.

Mazaheri, A., \& Jensen, O. (2010). Rhythmic pulsing: Linking ongoing brain activity with evoked responses. Frontiers in Human Neuroscience, 4, 177.

McEvoy, L. K., Smith, M. E., \& Gevins, A. (2000). Test-retest reliability of cognitive EEG. Clinical Neurophysiology, 111, 457-463.

Montez, T., Poil, S. S., Jones, B. F., Manshanden, I., Verbunt, J. P., van Dijk, B. W., . . Linkenkaer-Hansen, K. (2009). Altered temporal correlations in parietal alpha and prefrontal theta oscillations in early-stage Alzheimer disease. Proceedings of the National Academy of Sciences of the United States of America, 106, 1614-1619.

Moretti, D. V., Babiloni, C., Binetti, G., Cassetta, E., Dal Forno, G., Ferreric, F., ... Rossini, P. M. (2004). Individual analysis of EEG frequency and band power in mild Alzheimer's disease. Clinical Neurophysiology, 115, 299-308.

Moretti, D. V., Miniussi, C., Frisoni, G., Zanetti, O., Binetti, G., Geroldi, C., ... Rossini, P. (2007). Vascular damage and EEG markers in subjects with mild cognitive impairment. Clinical Neurophysiology, 118, 18661876.

Mundy-Castle, A. C. (1958). Electrophysiological correlates of intelligence. Journal of Personality, 26, 184-199.

Mundy-Castle, A. C., \& Nelson, G. K. (1960). Intelligence, personality and brain rhythms in a socially isolated community. Nature, 185, 484-485.

Näpflin, M., Wildi, M., \& Sarnthein, J. (2007). Test-retest reliability of resting EEG spectra validates a statistical signature of persons. Clinical Neurophysiology, 118, 2519-2524.

Näpflin, M., Wildi, M., \& Sarnthein, J. (2008). Test-retest reliability of EEG spectra during a working memory task. Neuroimage, 43, 687-693.

Niedermeyer, E., \& Lopes da Silva, F. H. (Eds.). (1999). Electroencephalography: Basic principles, clinical applications, and related fields (2nd ed.). Philadelphia, PA: Lippincott Williams \& Wilkins.

Oostenveld, R., Fries, P., Maris, E., \& Schoffelen, J. M. (2011). FieldTrip: Open source software for advanced analysis of MEG, EEG, and invasive electrophysiological data. Computational Intelligence \& Neuroscience, 2011, 156869.

Oostenveld, R., \& Praamstra, P. (2001). The five percent electrode system for high-resolution EEG and ERP measurements. Clinical Neurophysiology, 112, 713-719.

Pollock, V. E., Schneider, L. S., \& Lyness, S. A. (1991). Reliability of topographic quantitative EEG amplitude in healthy late-middle-aged and elderly subjects. Electroencephalography \& Clinical Neurophysiology, 79, 20-26.

Prichep, L. S. (2007). Quantitative EEG and electromagnetic brain imaging in aging and in the evolution of dementia. Annals of the New York Academy of Sciences, 1097, 156-167.

Raz, N., Ghisletta, P., Rodrigue, K. M., Kennedy, K. M., \& Lindenberger, U. (2010). Trajectories of brain aging in middle-aged and older adults: Regional and individual differences. NeuroImage, 51, 501-511.

Raz, N., Lindenberger, U., Rodrigue, K. M., Kennedy, K. M., Head, D., Williamson, A., ... Acker, J. D. (2005). Regional brain changes in aging healthy adults: General trends, individual differences and modifiers. Cerebral Cortex, 15, 1676-1689.

Raz, N., Yang, Y. Q., Rodrigue, K. M., Kennedy, K. M., Lindenberger, U., \& Ghisletta, P. (2012). White matter deterioration in 15 months: Latent growth curve models in healthy adults. Neurobiology of Aging, 33, 429.e1-429.e5.

Robinson, P. A., Rennie, C. J., Rowe, D. L., O'Connor, S. C., Wright, J. J., Gordon, E., ... Whitehouse, R. W. (2003). Neurophysical modeling of brain dynamics. [Supplement 1] Neuropsychopharmacology, 28, S7479.

Salinsky, M. C., Oken, B. S., \& Morehead, L. (1991). Test-retest reliability in EEG frequency analysis. Electroencephalography \& Clinical Neurophysiology, 79, 382-392.

Sarnthein, J., Andersson, M., Zimmermann, M. B., \& Zumsteg, D. (2009). High test-retest reliability of checkerboard reversal visual evoked potentials (VEP) over 8 months. Clinical Neurophysiology, 120, 1835-1840.

Schmiedek, F., Lövdén, M., \& Lindenberger, U. (2010). Hundred days of cognitive training enhance broad cognitive abilities in adulthood: Findings from the COGITO study. Frontiers in Aging Neuroscience, 2, pii: 27.

Smit, C. M., Wright, M. J., Hansell, N. K., Geffen, G. M., \& Martin, N. G. (2006). Genetic variation of individual alpha frequency (IAF) and alpha power in a large adolescent twin sample. International Journal of Psychophysiology, 61, 235-243.

Smit, D. J., Posthuma, D., Boomsma, D. I., Geus, E. J., Smit, D. J. A., \& Geus, E. J. C. (2005). Heritability of background EEG across the power spectrum. Psychophysiology, 42, 691-697.

Smit, D. J., Stam, C. J., Posthuma, D., Boomsma, D. I., \& de Geus, E. J. (2008). Heritability of "small-world" networks in the brain: A graph theoretical analysis of resting-state EEG functional connectivity. Human Brain Mapping, 29, 1368-1378.

Smit, D. J. A., Boomsma, D. I., Schnack, H. G., Hulshoff Pol, H. E., \& de Geus, E. J. C. (2012). Individual differences in EEG spectral power reflect genetic variance in gray and white matter volumes. Twin Research and Human Genetics, 15, 384-392.

Spearman, C. (1904). The proof and measurement of association between two things. The American Journal of Psychology, 15, 72-101.

Stomrud, E., Hansson, O., Minthon, L., Blennow, K., Rosen, I., \& Londos, E. (2010). Slowing of EEG correlates with CSF biomarkers and reduced cognitive speed in elderly with normal cognition over 4 years. Neurobiology of Aging, 31, 215-223.

Surwillo, W. W. (1961). Frequency of the "alpha" rhythm, reaction time and age. Nature, 191, 823-824.

Surwillo, W. W. (1963). The relation of simple response time to brain-wave frequency and the effects of age. Electroencephalography \& Clinical Neurophysiology, 15, 105-114.

Szelies, B., Grond, M., Herholz, K., Kessler, J., Wullen, T., \& Heiss, W. D. (1992). Quantitative EEG mapping and PET in Alzheimer's disease. Journal of the Neurological Sciences, 110, 46-56.

Szelies, B., Mielke, R., Kessler, J., \& Heiss, W. D. (1999). EEG power changes are related to regional cerebral glucose metabolism in vascular dementia. Clinical Neurophysiology, 110, 615-620.

Tuladhar, A. M., ter Huurne, N., Schoffelen, J. M., Maris, E., Oostenveld, R., \& Jensen, O. (2007). Parieto-occipital sources account for the increase in alpha activity with working memory load. Human Brain Mapping, 28, 785-792.

Valdes-Hernandez, P. A., Ojeda-Gonzalez, A., Martinez-Montes, E., LageCastellanos, A., Virues-Alba, T., Valdes-Urrutia, L., . . . Valdes-Sosa, P. A. (2010). White matter architecture rather than cortical surface area correlates with the EEG alpha rhythm. NeuroImage, 49, 2328-2339.

van Beijsterveldt, C. E. M., \& Boomsma, D. I. (1994). Genetics of the human electroencephalogram (EEG) and event-related brain potentials (ERPs): A review. Human Genetics, 94, 319-330.

van Beijsterveldt, C. E. M., \& van Baal, G. C. M. (2002). Twin and family studies of the human electroencephalogram: A review and a metaanalysis. Biological Psychology, 61, 111-138.

Van Dis, H., Corner, M., Dapper, R., Hanewald, G., \& Kok, H. (1979). Individual differences in the human electroencephalogram during quiet wakefulness. Electroencephalography and Clinical Neurophysiology, 47, 87-94.

Vogel, F. (1970). The genetic basis of the normal human electroencephalogram (EEG). Humangenetik, 10, 91-114.

(Received June 8, 2012; AcCePted February 21, 2013) 